\title{
Dielectric Nanoparticles Coated upon Silver Hollow Nanosphere as an Integrated Design to Reinforce SERS Detection of Trace Ampicillin in Milk Solution
}

\author{
Han Lee ${ }^{1}$, Jia-Wei Yang ${ }^{1}$, Jiunn-Der Liao ${ }^{1,2, *}$, Jaya Sitjar ${ }^{1}$, Bernard Haochih Liu ${ }^{1}$, \\ Kundan Sivashanmugan ${ }^{3}$, Wei-En $\mathrm{Fu}^{4}$ and Guo Dung Chen ${ }^{4}$ \\ 1 Department of Materials Science and Engineering, National Cheng Kung University, 1 University Road, \\ Tainan 701, Taiwan; rick594007@hotmail.com (H.L.); jaron83806@gmail.com (J.-W.Y.); \\ jaya.sitjar@gmail.com (J.S.); hcliu@mail.ncku.edu.tw (B.H.L.) \\ 2 Medical Device Innovation Center, National Cheng Kung University, 1 University Road, Tainan 701, Taiwan \\ 3 School of Electrical Engineering and Computer Science, Oregon State University, 1148 Kelley Engineering \\ Center, Corvallis, OR 97331, USA; sivashanmugan87@gmail.com \\ 4 Center for Measurement Standards, Industrial Technology Research Institute, No. 321, Kuang Fu Road, \\ Section 2, Hsinchu 300, Taiwan; weienfu@itri.org.tw (W.-E.F.); Eric_chen@itri.org.tw (G.D.C.) \\ * Correspondence: jdliao@mail.ncku.edu.tw; Tel.: +886-6-2757575 (ext. 62971); Fax: +886-6-2346290
}

Received: 19 March 2020; Accepted: 14 April 2020; Published: 15 April 2020

\begin{abstract}
Surface-enhanced Raman scattering (SERS) technique is competent to trace detection of target species, down to the single molecule level. The detection sensitivity is presumably degraded by the presence of non-specific binding molecules that occupy a SERS-active site (or hot spot) on the substrate surface. In this study, a silver hollow nano-sphere (Ag HNS) with cavity has been particularly designed, followed by depositing dielectric nanoparticles (Di NPs) upon Ag HNS. In the integrated nanostructures, Di NPs/Ag HNS were furthermore confirmed by cutting through the cross sections using the Focused Ion Beam (FIB) technique, which provides the Scanning Electron Microscope (SEM) with Energy-dispersive Spectroscope (EDS) mode for identifying the distribution of Di NPs upon Ag HNS. The results have indicated that Di NPs/Ag HNS exhibits small diameter of cavity, and among Di NPs in this study, $\mathrm{Al}_{2} \mathrm{O}_{3}$ with lower dielectric constant provides a much higher SERS enhancement factor (e.g., $\sim 6.2 \times 10^{7}$ ). In this study, to detect trace amounts (e.g., $0.01 \mathrm{ppm}$ ) of Ampicillin in water or milk solution, $\mathrm{Al}_{2} \mathrm{O}_{3} \mathrm{NPs} / \mathrm{Ag} \mathrm{HNS}$ was found to be more efficient and less influenced by non-specific binding molecules in milk. A substrate with integrated plasmonic and dielectric components was designed to increase the adsorption of target species and to repulse non-specific binding molecules from SERS-active sites.
\end{abstract}

Keywords: surface-enhanced Raman scattering; non-specific binding; silver hollow nanosphere; dielectric nanoparticle; ampicillin

\section{Introduction}

The detection of contaminants or hazardous substances by a precise, sensitive-to-target species, and convenient device is of great interest for the fields such as health care, food preparation, and environmental sampling [1-3]. Among them, ampicillin residue in food and to the environment provokes great public concern since it could pose potential health risks not only to the consumers but also the Earth $[4,5]$. Various analytical methods, including gas chromatography $[6,7]$ and high-performance liquid chromatography [8], have been applied for trace detection of ampicillin in a solution. However, these approaches usually need expensive laboratory facilities and involve time-consuming and costly sample preparation [9]. Thus, alternative research has been conducted to develop advanced detection 
techniques to provide rapid, food quality preserved, and bio-safety evaluation or analysis for related laboratories or industries [9-11].

Surface-enhanced Raman scattering (SERS) technique delivers fingerprint information about a given substance using nearly roughened metal surfaces, metal nanoparticles (NPs), or metal nanostructures owing to their strong effect on the Raman-active peak(s) of target molecule. The enhancement of Raman-active modes is mainly due to the contribution of two effects through chemical mechanism (CM) and electromagnetic mechanism (EM) [12-15]. The CM depends on the adsorption of target molecules upon the "hot spots", which are generated at SERS-active sites; charge transfer occurs between the target molecule and the substrate, which may be enhanced by the polarizability of the molecule [16]. On the other hand, the EM relies on the physical attributes of the substrate as it is highly dependent on the composition, shape, and size of the metal substrate, which affect localized surface plasmon resonance (LSPR) in the metallic nanostructures. Therefore, available hot spots are formed in between the plasmonic nanostructures [15]. Aside from the mentioned factors, the intensity of SERS signals is also affected by the induced Raman laser wavelength, and thereafter, the interactions of target molecules toward the substrate $[17,18]$.

It has been widely accepted that the formation of Raman-active sites generates a highly enhanced EM field that leads to high enhancement factor (EF). The "hot spots" can be observed or even predicted using computer simulation and modeling to describe the quantum effect on sub-nanometer gaps [19]. Usually, a noble metal surface with a designed structure of e.g., high roughness [20], sharp edges [21], hollow cavities [22], is advantageous to produce an enhanced EM as well as multiple surface plasmon [23]. In addition, a thin-film Ag having a nano- or micro-scale roughness is a promising SERS-active substrate base [23-25]. By manipulating Ag thin film as a hollow nano-sphere (HNS) structure, a larger effective surface area is formed, and with the resulting cavity, a strong EM effect could be achieved, in particular upon the intra-Ag HNS and in the cavity [25-27].

Metal/semiconductor composite nanostructures have greater surface plasmon resonance-induced enhancement in optical properties, which originate from the electron and energy transfer between the metal-semiconductor interfaces [27-29]. The charge separation at the interface enhances EM field, which induces the effect of SERS and contributes an enhancement of $10^{2} \sim 10^{3}$ times more than that at the metallic nanostructure alone [30,31]. It is also known that dielectric materials have various dielectric constants, electron affinities, and Fermi levels [10,31-33]. As dielectric NPs (Di NPs), such as $\mathrm{HfO}_{2}$, $\mathrm{TiO}_{2}$, and $\mathrm{Al}_{2} \mathrm{O}_{3}$, are attached upon e.g., hollow nanosphere (HNS), presumably the electron-hole pairs will be much reduced from recombination [31] and thus a significant contribution to the effect of SERS can be anticipated [34].

Antibiotic residue is mostly found in water or milk solution, which is suitable for the application of Raman spectroscopy [35]. However, trace detection under a non-fully wettable surface and the presence of non-specific binding (NSB) molecules upon the substrate surface is limited [36,37]. These drawbacks should be compensated through the improvement of substrate surface as a Raman-active property may contribute to Raman intensity for an $\mathrm{EF}$ of $10^{3} \sim 10^{7}[33,38]$. In this work, a combination of Di NPs and Ag HNS is particularly designed for trace detection of Raman-active ampicillin [39] in water or in milk solution. Silver hollow nanospheres (Ag HNS) were formed by depositing Ag onto a template of regularly-arranged polystyrene nanoparticles that were subsequently removed, leaving hollow Ag shells; dielectric NPs were then deposited onto the Ag HNS, denoted as Di NPs/Ag HNS. Aside from the intra-Ag HNS serving as SERS hotspots, from recent reports in association with this study, the use of Di NPs is to enhance EM field [40] and is challenging for reducing the attachment of NSB molecules from e.g., milk solution [41]. This powerful integration is furthermore anticipated to realize single-target-molecule detection in a much complex environment for e.g., food control [42] and cellular quality in medium [43]. 


\section{Experimental Section}

\subsection{Fabrications of PS, Ag HNS, and Di NPs/Ag HNS}

Uniform polystyrene beads (PS_Bs), with a diameter of 130, 240, and $260 \mathrm{~nm}$ that were synthesized through surfactant-free emulsion polymerization, were first deposited onto clean $2 \times 2 \mathrm{~cm}^{2} \mathrm{Si}$ substrates, by drawing out the Si substrates that were briefly immersed in PS_Bs suspended in water, as illustrated in Figure $1 \mathrm{a}(\mathrm{i}-\mathrm{v})$. The PS-coated Si was then subjected to slight annealing at $50{ }^{\circ} \mathrm{C}$ for $10 \mathrm{~min}$ [44], ensuring that all the solvents have evaporated and that the PS_Bs are fixed onto the surface of the Si. As shown in Figure 1a(vi), Ag thin film was then deposited onto PS_Bs/Si by an e-beam evaporator (VT1-10CE, ULVAC, Chigasaki, Japan), followed by annealing at $400{ }^{\circ} \mathrm{C}$ for $45 \mathrm{~min}$ to remove the PS_Bs. The heat-treated Ag thin film without PS_Bs then became a crystalline Ag shell with a cavity; the as-formed structure is described as Ag HNS. Based on the sizes of the as-prepared PS_Bs, 130, 240, and $260 \mathrm{~nm}$, three Ag HNSs: Ag HNS_130,_240, and _260 were employed, as shown in Figure 1a(i-vii). Three different Di NPs: $\mathrm{HfO}_{2}, \mathrm{TiO}_{2}$, and $\mathrm{Al}_{2} \mathrm{O}_{3}$, were then deposited on $\mathrm{Ag}$ HNS through an electron beam evaporator (VT1-10CE, ULVAC Inc., Tokyo, Japan) with a thickness of $\sim 1.5 \mathrm{~nm}$ and at a deposition rate of $0.1 \AA /$ s. Three Di NPs/Ag HNSs were fabricated: $\mathrm{HfO}_{2} /, \mathrm{TiO}_{2} /$, and $\mathrm{Al}_{2} \mathrm{O}_{3} / \mathrm{Ag} \mathrm{HNS}$, were used for the study, as shown in Figure 1b(i,ii). The Di NPs were loosely attached upon Ag HNS, which results in a broad distribution over the SERS-active surface. It is conjecture that if there is a film-like $\mathrm{Di}$ NPs upon Ag HNS, the incident laser tends to interact with only Di NPs, rather than with the inclusion of Di NPs/Ag interface and Ag HNS, the effect of SERS is presumably reduced.
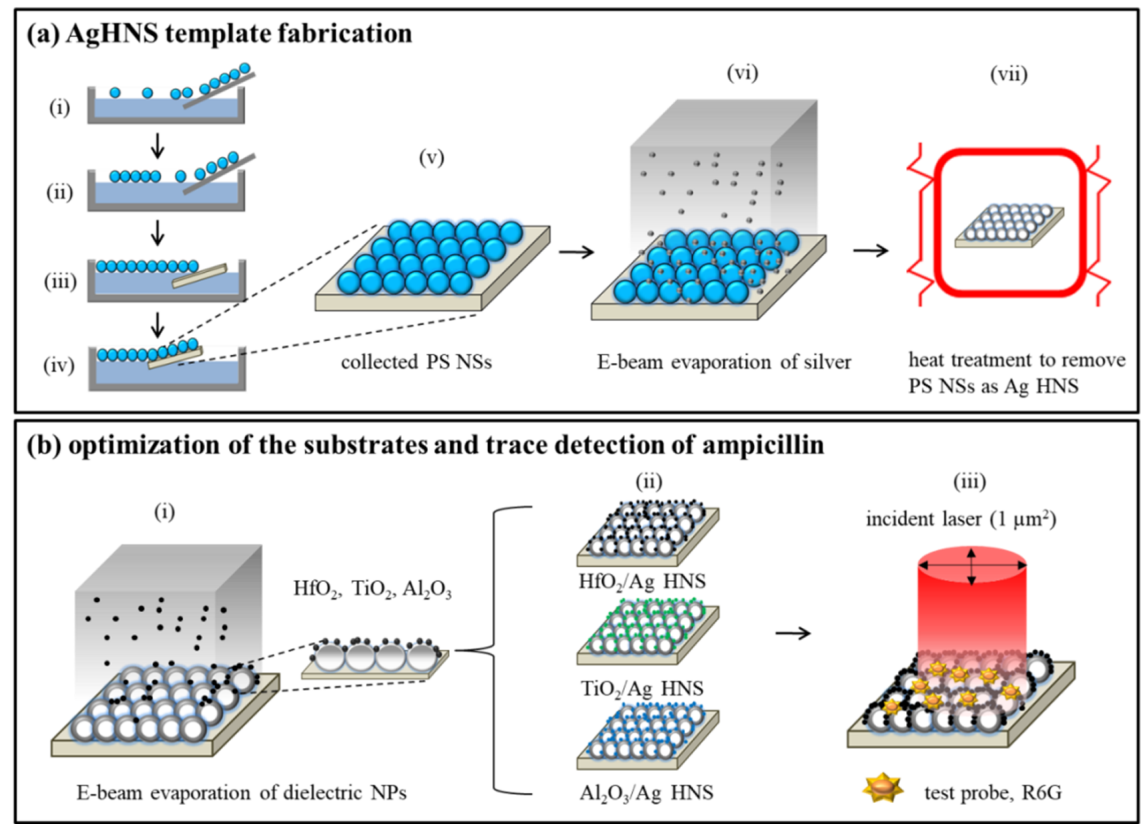

Figure 1. (a) Ag HNS template fabrication procedures: (i) PS_Bs suspension is pipetted onto an angled glass substrate and moved onto water/air interface; (ii) PS_Bs start assembling on water/air interface; (iii) as more suspensions join PS_Bs monolayer, a full coverage over the interface is obtained; (iv) a plate is then entered a water phase at a shallow angle of $\sim 10^{\circ}$ to transfer the monolayer; (v) PS_Bs of e.g., $130 \mathrm{~nm}$ are formed as a monolayer on Si substrate by the growth-at-interface method; (vi) subsequently e-beam evaporation of $20 \mathrm{~nm}$ Ag NPs is deposited on PS_Bs monolayer, and (vii) followed by heat treatment $\left(400{ }^{\circ} \mathrm{C}, 45 \mathrm{~min}\right)$ to release PS_Bs, Ag HNS is thereafter formed. (b) An optimization of Di NPs upon Ag HNS: (i) E-beam evaporation of Di NPs; (ii) three as formed samples: $\mathrm{HfO}_{2} /, \mathrm{TiO}_{2} /$, and $\mathrm{Al}_{2} \mathrm{O}_{3} / \mathrm{Ag}$ HNS; (iii) the test molecule, $\mathrm{R} 6 \mathrm{G}$ for the evaluation of EFs. 


\subsection{Structural and Morphological Characterization}

The surfaces of Di NPs/Ag HNS were characterized using high-resolution thermal FESEM (JSM-7000, JEOL, Tokyo, Japan), which was operated at an accelerating voltage of $10 \mathrm{kV}$. The compositions on the surface of Di NPs/Ag HNS were analyzed by a focused module of EDS. The cross-sectioning and imaging of Ag HNS were performed by a dual-focused ion and electron beam FIB/SEM (FEI Nova-200 NanoLab Compatible, Hillsboro, OR, USA) system.

\subsection{SERS Property of Ag HNS and Di NPs/Ag HNS}

Experiments in evaluating SERS properties were done with 5 replicates; as-prepared Ag HNS and Di NPs/Ag HNS were examined using Raman spectrometer (Renishaw, Wotton-under-Edge, UK) with an incident power of $3 \mathrm{~mW}$ and an air-cooled charge-coupled device as the detector. An amount of $2 \mu \mathrm{L}$ of R6G was dropped onto the substrate and left to dry in air at room temperature before acquiring the Raman spectra at an integration time of $30 \mathrm{~s}$.

Raman spectrometer is operated with the $50 \times$ objective of optical microscope, the spot size of Raman laser at a diameter of $1 \mu \mathrm{m}$, and the diode and He-Ne lasers at excitation wavelengths of $633 \mathrm{~nm}$ with gratings at 1800 lines $/ \mathrm{nm}$. The calibration of the spectrum was done first before taking any measurements with the use of a standard Si and at a laser power set at $100 \%$. The obtained Raman spectra were processed after adjusting background fluorescent signals and noise that may be induced by the use of an objective lens to focus the laser spot. Baseline correction and smoothing were performed in conjunction with each other to obtain accurately defined signals.

\subsection{Trace Detection of Ampicillin in Water and in Milk Solution}

The Di NPs/Ag HNS_130 was employed for trace detection of ampicillin in water and in milk solution. An appropriate amount of ampicillin (EMD Millipore Corp., Temecula, CA, USA) was added to $10 \mathrm{~mL}$ of deionized water to prepare standard solutions with the concentrations of 100,1 , and $0.01 \mathrm{ppm}$ for the studies. Milk solution was prepared as follows: $10 \mathrm{~mL}$ of commercially-available pasteurized milk (Uni-President Enterprises Corp., Tainan, Taiwan) was added to $500 \mathrm{~mL}$ of distilled water under vigorous stirring at room temperature to obtain a homogeneous solution. Note that the "raw milk" was commercially processed, ready for consumption, and thus pasteurized. This milk referred to it being "raw" as it was not mixed with anything else before diluting it with water or adding the sulfuric acid to remove the lipids. A lipid-removal procedure was then performed and lipids were pre-aggregated in milk by adding $5 \mu \mathrm{L}$ sulfuric acid per $1 \mathrm{~mL}$ milk solution at room temperature, at which point the lipids were aggregated, allowing the solids to be easily removed using a $0.2-\mu \mathrm{m}$ syringe filter, yielding a clear filtrate. Ampicillin was then added to the as-prepared homogeneous milk solution at a concentration of $0.01 \mathrm{ppm}$.

\subsection{Enhancement Factor Evaluation and Calculation}

To assess the SERS effect of the substrate, a normal Raman scattering is required as a benchmark for comparative analysis, in which each substrate could lead to a distinguished effect. The quantification effect value is called the $E F$ and is calculated in the Formula (1):

$$
E F=\frac{I_{S E R S}}{I_{\text {Bulk }}} \times \frac{N_{\text {Bulk }}}{N_{\text {SERS }}}
$$

where $N_{S E R S}$ and $N_{B u l k}$ are the numbers of probe molecules contributing to the SERS and non-SERS signal, respectively; and $I_{S E R S}$ and $I_{B u l k}$ are the intensities of the selected scattering bands in the SERS and non-SERS spectra, respectively. The probed molecules are assumed to distribute uniformly on the substrates. The number of probe molecules located in the focus volume within the bulk sample $N_{\text {Bulk }}$ can be estimated by Formula (2):

$$
N_{B u l k}=A_{l s} h \frac{\rho}{m}
$$


where $A_{l s}$ is the laser spot area (diameter: $\left.1 \mu \mathrm{m}\right) ; h$ is the focus length $(19 \mu \mathrm{m}) ; \rho$ is the density of solid R6G $\left(1.26 \mathrm{~g} / \mathrm{cm}^{3}\right)$; and $\mathrm{m}$ is molecular weight of R6G (479 $\left.\mathrm{g} / \mathrm{mole}\right)$. The number of R6G molecules adsorbed on the SERS-active substrate surface $N_{\text {SERS }}$ can be estimated by Formula (3):

$$
N_{S E R S}=\frac{A_{l s}}{A_{c}} \frac{A_{S C}}{A_{m}}
$$

where $A_{c}, A_{s c}$, and $A_{m}$ represent the area of a circle with a diameter equal with that of one Ag HNS, the area of a spherical calotte, and the area occupied by a single R6G molecule (59.9 $\left.\AA^{2}\right)$, respectively.

\section{Results and Discussion}

\subsection{Size and Dimension of $\mathrm{Ag} H \mathrm{HNS}$}

In Figure 2a-f, surface morphologies of the as-prepared Ag and Ag HNSs with different sizes and dimensions were verified using Field Emission SEM (FESEM). PS_Bs of 130, 240, and $260 \mathrm{~nm}$ in diameter were successfully prepared and employed as the templates to assist the formation of the substrates. Ag_x and Ag HNS_x denote the substrates before and after the PS_Bs template removal; $x$ represents the diameter of PS_Bs template used, which in the cases of this study are 130,240, and $260 \mathrm{~nm}$. Three types of substrates with cavities, according to PS_Bs template sizes, were thus produced: Ag HNS_130, Ag HNS_240, and Ag HNS_260. The inner structure in Ag HNS was furthermore studied by cutting through cavities using a Focused Ion Beam (FIB) with an equipped SEM (FIB/SEM) under a magnification of 100,000×. Owing to e-beam evaporation of Ag toward PS_Bs, followed by annealing to remove them, it is likely that the as-formed cavities s are slightly smaller than the original size and dimension of PS_Bs [37]. The diameters of Ag HNSs were then measured by SEM as 130, 235, and 255 nm for Ag HNS_130,_240,_260, respectively. The as-measured size and dimension of PS_Bs and cavities did not show significant difference. It is most probably contributed by the rigidity of Ag shells and an appropriate control of released PS_Bs $[29,45]$.

In Figure 2g, the cross-section of Ag HNS_130 is demonstrated. The rectangular dark area marked as \#1 contains the cross-sectioned Ag HNSs with cavities, which are distributed between the annealed $\mathrm{Ag}$ shells and Si substrate. To have a better description on cavities, the larger rectangular area marked as \#2 in Figure $2 \mathrm{~g}$ was enlarged and illustrated in Figure $2 \mathrm{~h}$. On the left side of Figure $2 \mathrm{~h}$, two complete Ag HNSs were shown, whereas on the right side, two distorted Ag HNSs caused by an unparalleled direction of FIB/SEM manipulation with respect to the order of Ag HNSs were also demonstrated. The result reveals a clear formation of HNS between the annealed Ag shells and Si substrate. In our further applications, the well-ordered Ag HNSs with cavities are hence presumed. 


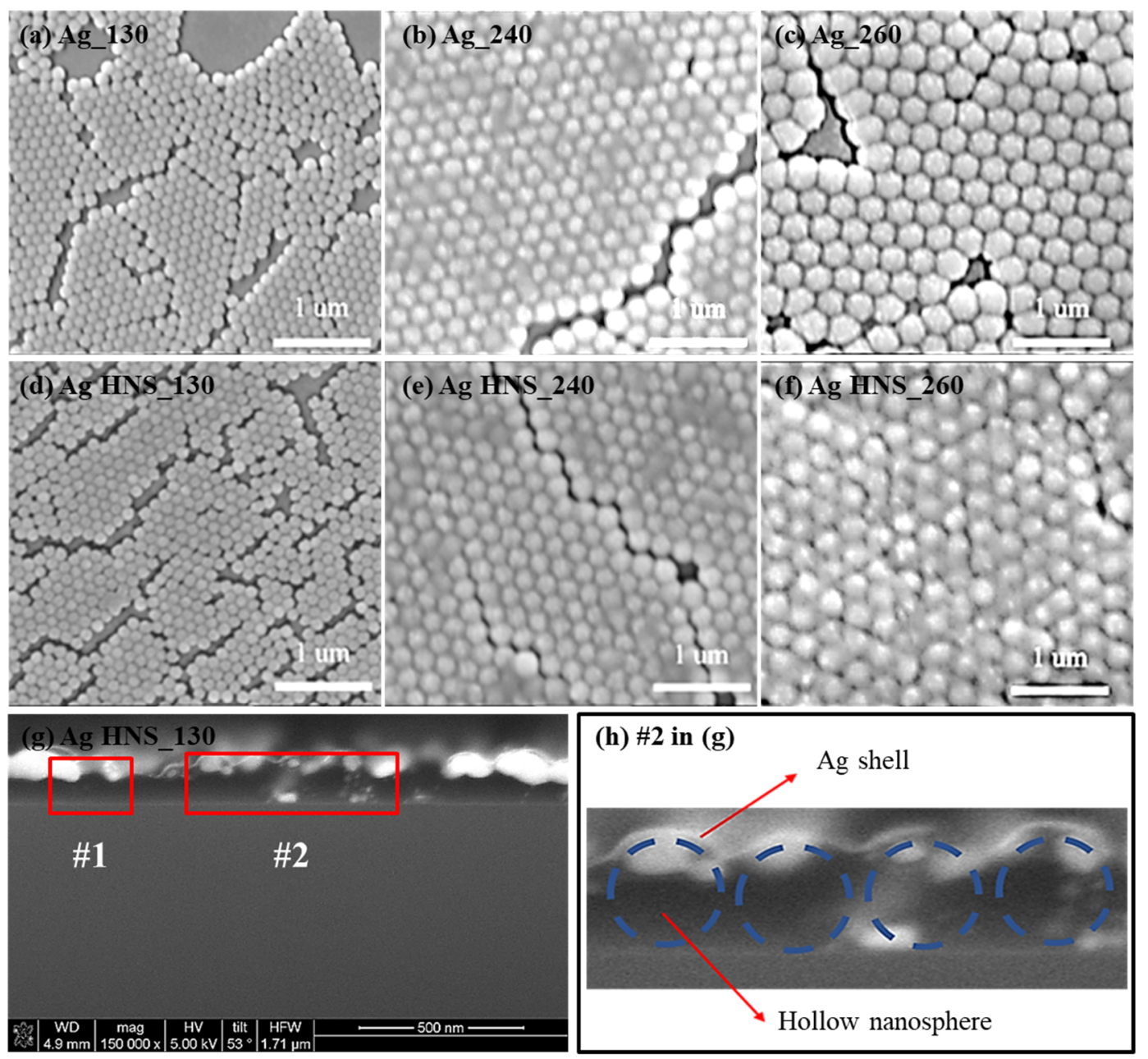

Figure 2. SEM images of Ag on PS_Bs with the diameters of 130, 240, and $260 \mathrm{~nm}$ and heat-treated Ag HNS were respectively shown: (a) Ag_130, (b) _240, (c) _260, (d) Ag HNS_130, (e) _240, and (f) _260. The magnification is $25,000 \times$. To examine the cross section of $(\mathbf{g})$ Ag HNSs_130, the sample was cut by FIB/SEM. A magnification of 100,000× was shown. The HNS structures between Si substrate and Ag shell were cut and shown (boxed in red and marked as \#1) and (h) a closer examination of ( $(\mathbf{g})$ with that of $150,000 \times$ (blue circles marked as \#2).

\subsection{Di NPs upon Ag HNS}

In Figure 3a-c, FESEM photo-images for the attachment of Di NPs: $\mathrm{HfO}_{2}, \mathrm{TiO}_{2}$, and $\mathrm{Al}_{2} \mathrm{O}_{3}$ upon Ag HNSs were shown under a magnification of 90,000×. Apparently, their original sizes and dimensions of Ag HNSs still remained. To examine the composition and the distribution of Di NPs upon Ag HNS, a focused module of Energy Dispersive X-ray Spectrometer (EDS) was applied. In Figure $2 \mathrm{~d}-\mathrm{f}$, taking the images from Figure $3 \mathrm{a}-\mathrm{c}$, single $\mathrm{HfO}_{2} /, \mathrm{TiO}_{2} /$, and $\mathrm{Al}_{2} \mathrm{O}_{3} / \mathrm{Ag} \mathrm{HNSs}$ were respectively illustrated and enlarged on their top-right columns. In these EDS mapping images, the blue and green dots represent the background of $\mathrm{Ag}$ shell and $\mathrm{O}$ element, while the red dots represent $\mathrm{Hf}$ in $3 \mathrm{~d}$, $\mathrm{Ti}$ in $3 \mathrm{e}$, and $\mathrm{Al}$ in $3 f$. The result reveals that the attachment of $\mathrm{HfO}_{2}, \mathrm{TiO}_{2}$ or $\mathrm{Al}_{2} \mathrm{O}_{3}$ upon $\mathrm{Ag}$ HNS is well confirmed through the EDS mapping process. Presumably, e-beam evaporation of Di NPs may result in random scattering of non-aggregated NPs, the possibility of such NPs upon Ag HNS is expected to be equal. Based on this assumption, a good distribution of Di NPs over the surface of Ag HNS can be presumably achieved. 

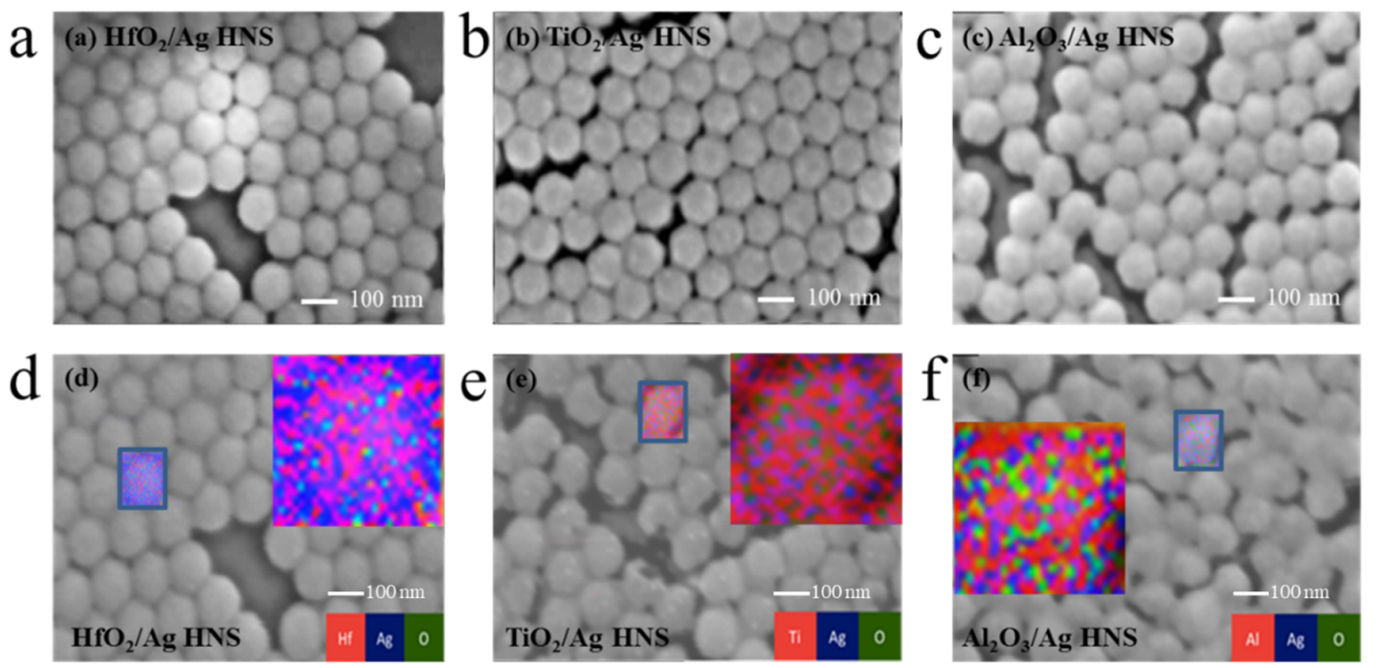

Figure 3. SEM images of Di NPs/Ag HNS_130: (a) $\mathrm{HfO}_{2} /$, (b) $\mathrm{TiO}_{2} /$, and (c) $\mathrm{Al}_{2} \mathrm{O}_{3} / \mathrm{Ag}$ HNS with the magnification of $90,000 \times$. The uniform arrangement of dots represents that different Di NPs were arranged on Ag HNS surface. The EDS mappings of (d) $\mathrm{HfO}_{2} /$, (e) $\mathrm{TiO}_{2} /$, and (f) $\mathrm{Al}_{2} \mathrm{O}_{3} / \mathrm{Ag}$ HNS were shown with a scanned area of single Ag HNS. It demonstrated aligned bulges, corresponding to Di NPs upon Ag HNS.

\subsection{SERS Property of Di NPs/Ag HNS}

The concept of designing Di NPs/Ag HNS is to obtain an integrated SERS property with the synergy from the characteristic of Ag as SERS-active surface, an enhanced plasmonic effect inside Ag shell and the contribution of dielectric property at the interface between Ag shell and Di NPs when a Raman laser with an appropriate wavelength is induced. To verify their SERS property, a molecular probe $\mathrm{R} 6 \mathrm{G}$ was firstly used to test the respective substrates, i.e., $\mathrm{Ag} \mathrm{HNS}, \mathrm{Al}_{2} \mathrm{O}_{3} /, \mathrm{HfO}_{2} /$, and $\mathrm{TiO}_{2} / \mathrm{Ag}$ HNS. In Figure 4, the characteristic peaks of R6G molecule are marked at: $611 \mathrm{~cm}^{-1}$ (C-C-C ring in plane bend), $773 \mathrm{~cm}^{-1}$ (C-C-C ring in plane bend), $1186 \mathrm{~cm}^{-1}$ (C-H in plane bend), $1309 \mathrm{~cm}^{-1}$ (C-O-C stretching), $1361 \mathrm{~cm}^{-1}$ (arom. C-C stretching), $1509 \mathrm{~cm}^{-1}$ (arom. C-C stretching), $1574 \mathrm{~cm}^{-1}$ (arom. C-C stretching), and $1649 \mathrm{~cm}^{-1}$ (arom. C-C stretching).

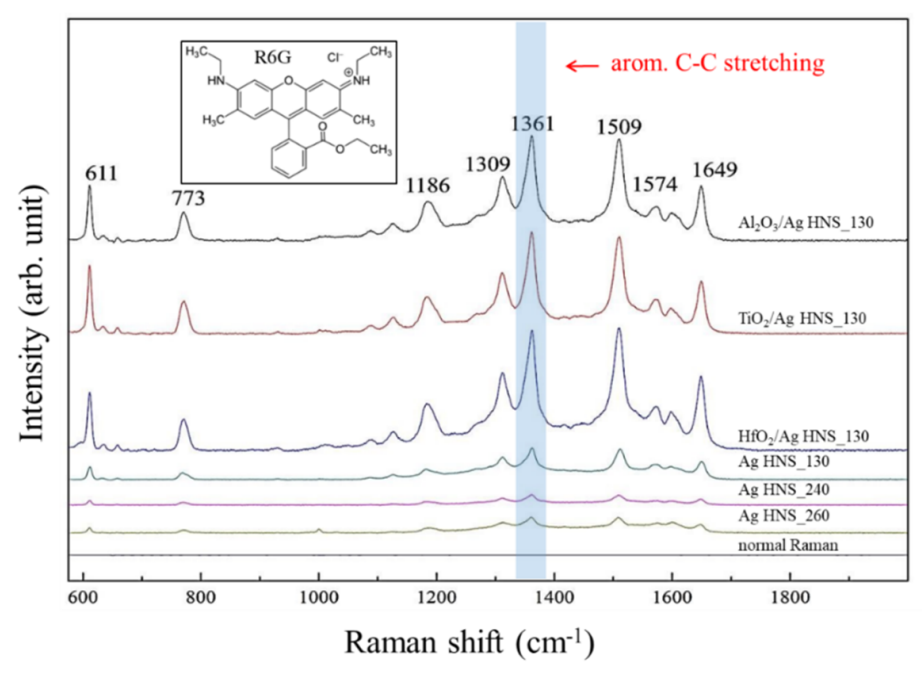

Figure 4. SERS spectra of $\mathrm{R} 6 \mathrm{G}$, as a probe molecule, upon $\mathrm{Ag} \mathrm{HNS}, \mathrm{Al}_{2} \mathrm{O}_{3} /, \mathrm{HfO}_{2} /$, and $\mathrm{TiO}_{2} / \mathrm{Ag} \mathrm{HNS}$. 
By taking the characteristic peak at $1361 \mathrm{~cm}^{-1}$ as the reference, Raman intensities, as compared to Di NPs/Ag HNS with Ag HNSs, significantly increased, as shown in Table 1. For examples, the EFs of Di NPs/Ag HNS_130 are 3.2-3.8 times higher than that of Ag HNS_130. Based on the equations (2.1), (2.2), and (2.3), $I_{\text {SERS }}$ is the Raman signal intensity at $1361 \mathrm{~cm}^{-1}$ for each substrate, $I_{B u l k}$ is 25 after Raman spectral analysis, $N_{\text {Bulk }}$ is estimated around $3.9 \times 10^{10}$ molecules, and $N_{\text {SERS }}$ is estimated as a value of $2.6 \times 10^{6}$. The results indicate that (1) the EF of Ag HNS shows slightly higher as the size and dimension of cavity is smaller [16]; (2) all the Di NPs/Ag HNS_130 have EFs significantly higher than Ag HNSs and greater than $10^{7}$; (3) $\mathrm{Al}_{2} \mathrm{O}_{3} / \mathrm{Ag}$ HNS_130 has the largest EF with a value of $6.2 \times 10^{7}$, which also shows that Ag HNS with the attachment of lower dielectric constant NPs results in a high EF [44]. Note that the values of dielectric constant for $\mathrm{Al}_{2} \mathrm{O}_{3}, \mathrm{HfO}_{2}$, and $\mathrm{TiO}_{2} /$ are 9-10, 20-30, and 10-85, respectively [46,47]. In general, for a SERS-active substrate with an EF of $10^{7}$ to $10^{8}$ or higher, it can provide the SERS property with a capability of single-molecule detection [48]. In any case, by increasing the specific surface area of the SERS-active substrate, more hot spots are likely formed that simultaneously increase the resulting Raman signal. If the bead size is decreased, the specific surface area tends to be augmented, consequently the Raman signal is enhanced owing to the presence of a high number of hot spots. In addition, the dielectric NPs not only increase the specific surface area but also induce chemical enhancement mechanism to occur owing to the involvement of charge transfers.

Table 1. The EFs of various substrates, obtained from Figure 4.

\begin{tabular}{|c|c|c|c|}
\hline \multirow{2}{*}{ Substrates } & \multicolumn{3}{|c|}{ Raman Laser Wavelength of $633 \mathrm{~nm}$ at the Characteristic Peak of $1361 \mathrm{~cm}^{-1}$} \\
\hline & $I_{\text {SERS }}\left(\times 10^{4}\right)$ & $N_{S E R S}\left(\times 10^{6}\right)$ & $E F\left(\times 10^{7}\right)$ \\
\hline Ag HNS_130 & 2.7 & 2.6 & 1.6 \\
\hline $\mathrm{HfO}_{2} / \mathrm{Ag} \mathrm{HNS}$ & 8.9 & 2.6 & 5.4 \\
\hline $\mathrm{TiO}_{2} / \mathrm{Ag} \mathrm{HNS}$ & 8.7 & 2.6 & 5.2 \\
\hline $\mathrm{Al}_{2} \mathrm{O}_{3} / \mathrm{Ag} \mathrm{HNS}$ & 10.3 & 2.6 & 6.2 \\
\hline
\end{tabular}

\subsection{Di NPs/Ag HNS for Trace Detection of Antibiotic Residue in Water}

As indicated in Section 3.3, a smaller diameter of cavity tends to increase the enhancement of plasmonic effect inside Ag shell. Thus, in the following applications, Di NPs with Ag HNS_130 (shortened as Ag HNS) are employed for trace detection of antibiotic, e.g., ampicillin, residue in different solutions.

In Figure 5a-c, SERS spectra for ampicillin in water with the respective concentrations of 100, 1, and $0.01 \mathrm{ppm}$, using $\mathrm{HfO}_{2} /, \mathrm{Al}_{2} \mathrm{O}_{3} /$, and $\mathrm{TiO}_{2} / \mathrm{Ag} \mathrm{HNS}$ were demonstrated. Three characteristic peaks, at 1007, 1115, and $1447 \mathrm{~cm}^{-1}$, for Ampicillin molecule are broadly marked in the spectra [46]. Among them, the peak at $1007 \mathrm{~cm}^{-1}$ is the most prominent characteristic peak, which is derived from the benzene ring vibration, shown on the top-left side in Figure $5 \mathrm{~d}$. Note that the peak at $1594 \mathrm{~cm}^{-1}$ is another significant peak of ampicillin from $\mathrm{C}=\mathrm{C}$ stretching; it is usually affected by background (or fluorescent interference) while in detection, making its intensity hard to compare [49]. On the other hand, the peaks at $852 \mathrm{~cm}^{-1}$ and a broad one at around $1300-1400 \mathrm{~cm}^{-1}$ are most probably attributed to Ag-O associated effect, which indicates, in this study, the interactions between Di NPs and $\mathrm{Ag}$ or Ag-O [50]. In Figure 5d, by taking the peak at $1007 \mathrm{~cm}^{-1}$ as the reference, the relation of ampicillin's concentrations with respect to SERS intensities detected by three SERS-active substrates was illustrated. The results indicate that (1) SERS intensities increase with the addition of ampicillin for all these three substrates; (2) in consistence with dielectric constant studied in Section 3.3, $\mathrm{Al}_{2} \mathrm{O}_{3} / \mathrm{Ag}$ HNS exhibits sensitive with the increase of ampicillin's concentration in water, while $\mathrm{TiO}_{2} / \mathrm{Ag} \mathrm{HNS}$ is less sensitive; (3) in general, Di NPs/Ag HNSs are all competent for trace detection of ampicillin in water. However, their increased enhancements at these three characteristic peaks differ from the substrates and concentrations of ampicillin.

It is very likely that the adsorption mechanism of ampicillin on each substrate is varied owing to the electronic structures formed by the combined SERS effect of target molecule upon different $\mathrm{Di}$ 
NPs/Ag HNS. For example, as found in Figure $5 a-c$, there are some peaks on Di NPs/Ag HNS, and the peaks' intensity obviously increases on $\mathrm{Al}_{2} \mathrm{O}_{3} \mathrm{NPs} / \mathrm{Ag}$ HNS than on $\mathrm{TiO}_{2} \mathrm{NPs} / \mathrm{Ag}$ HNS. Thus, a strong interaction between $\mathrm{Al}_{2} \mathrm{O}_{3}$ and $\mathrm{Ag}$ leads to a modification of the electronic structure, while the significant characteristic peak $\left(1007 \mathrm{~cm}^{-1}\right)$ for three kinds of substrates is all derived from the benzene ring. The benzene ring molecules are weakly bonded to SERS substrate, and with excitation by laser light, the charge transfer occurs from the highest occupied molecular orbital region (HOMO) of ampicillin molecule to the metal's energy level, and then jumps to the lowest unfilled molecular orbital region (LUMO) of ampicillin molecule, finally returns to the ground state [50]. The result shown in Figure $5 \mathrm{~d}$ is thus consistent with the correlation of dielectric property with Ag shell when Raman laser is applied to detect Ampicillin molecules upon Di NPs/Ag HNS. It also corresponds to the detection of R6G molecule that $\mathrm{Al}_{2} \mathrm{O}_{3}$ with the lowest dielectric constant upon the similar structure of $\mathrm{Ag} \mathrm{HNS}$ has the highest SERS intensity and EF.
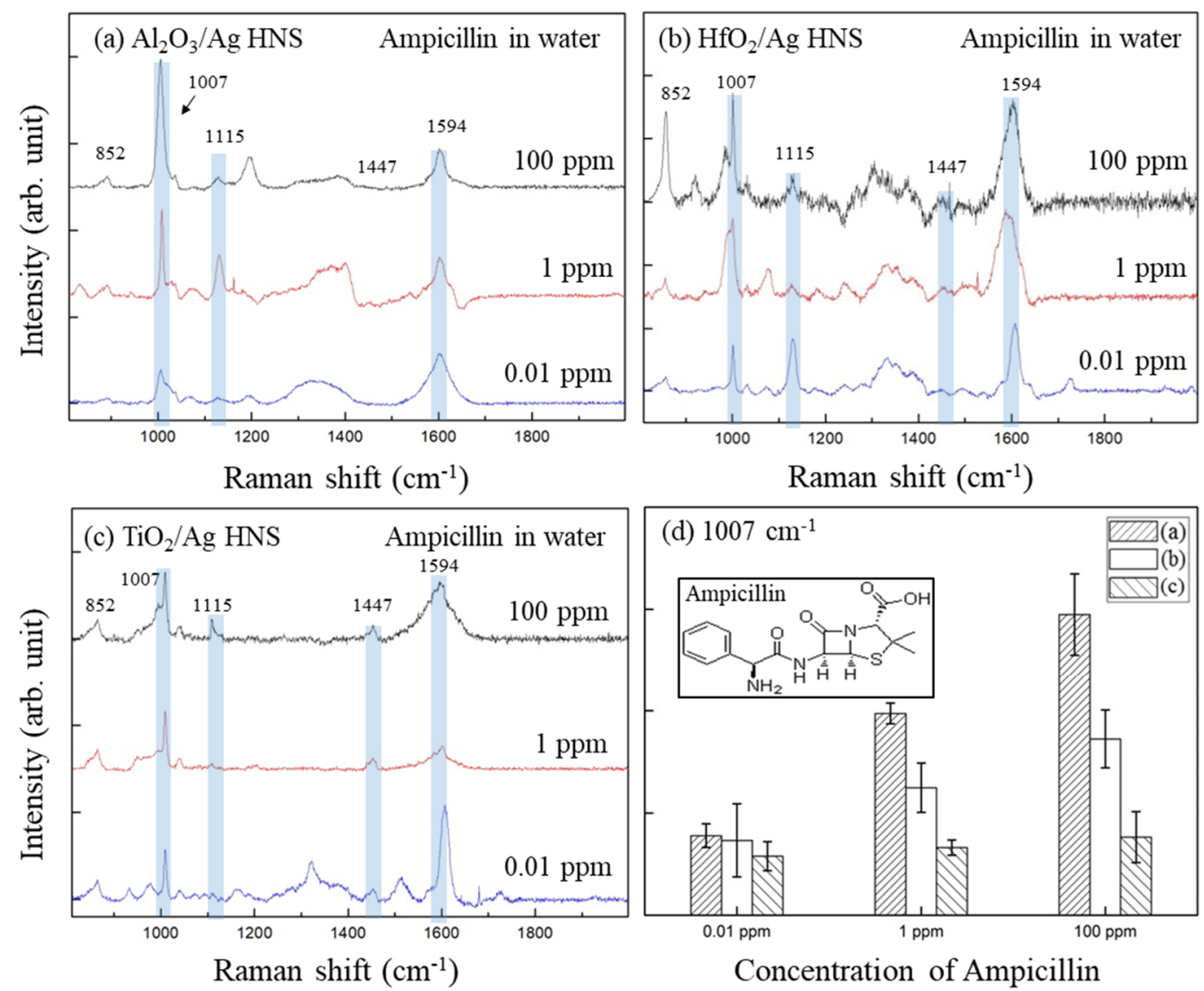

Figure 5. Examples of SERS spectra of ampicillin in water with respective concentrations of 100, 1.0, and 0.01 ppm upon (a) $\mathrm{Al}_{2} \mathrm{O}_{3} /$, (b) $\mathrm{HfO}_{2} /$, and (c) $\mathrm{TiO}_{2} / \mathrm{Ag} \mathrm{HNS}$. By taking different characteristic peaks: 1007,1115 , and $1447 \mathrm{~cm}^{-1}$ in different concentrations of ampicillin in water. Relative intensities of the peak at $1007 \mathrm{~cm}^{-1}$ were respectively compared with respect to dielectric type and ampicillin concentration $(\mathbf{d}),(n=5)$.

\subsection{Di NPs/Ag HNS for Trace Detection of Ampicillin in Milk Solution}

In Figure 6a, SERS spectra for ampicillin in milk solution with low concentration of $0.01 \mathrm{ppm}$ (e.g., to meet a standard for the residue regulation), using $\mathrm{Al}_{2} \mathrm{O}_{3} /, \mathrm{HfO}_{2} /$, and $\mathrm{TiO}_{2} / \mathrm{Ag} \mathrm{HNS}$ were demonstrated. Characteristic peaks at 1007, 1115, 1447, and $1594 \mathrm{~cm}^{-1}$ for ampicillin were still distinguishable [39]. It was also observed that there are peaks at $1300-1400 \mathrm{~cm}^{-1}$ due to the interactions 
between Di NPs and Ag or Ag-O surface, as previously discussed in Section 3.4 (i.e., Figure 5a-c). The result shows that Di NPs/Ag HNSs are competent to achieve trace detection of ampicillin molecule as low as $0.01 \mathrm{ppm}$ in milk solution. Among them, the peak at $1007 \mathrm{~cm}^{-1}$ is the most prominent peak. Note that milk is a complex fluid with an emulsion of suspended lipid droplets and a variety of sugars and proteins [39]. A lipid-removal procedure, as described in Experimental section, was thus necessarily prior to the sample into the detection [50,51]. The peak found at $1035 \mathrm{~cm}^{-1}$ presumably resulted from the surface of $\mathrm{Al}_{2} \mathrm{O}_{3} \mathrm{NPs} / \mathrm{Ag} \mathrm{HNS}$, which is likely the background thar contributed by the core shell structure of $\mathrm{Ag} \mathrm{HNS}[52,53]$ and $\mathrm{Al}_{2} \mathrm{O}_{3} \mathrm{NPs}$ upon $\mathrm{Ag} \mathrm{HNS}$, in the case of ampicillin in milk solution [44].

In Figure $6 \mathrm{~b}$, by taking these three peaks and low concentration (i.e., $0.01 \mathrm{ppm}$ ) of ampicillin in water and milk solution for a comparison, the results show the influence of ampicillin in different solutions. For the peak at $1007 \mathrm{~cm}^{-1}$, SERS intensities decrease as ampicillin is detected in milk solution; in general, for $\mathrm{Al}_{2} \mathrm{O}_{3} /, \mathrm{HfO}_{2} /$, and $\mathrm{TiO}_{2} / \mathrm{Ag} \mathrm{HNS}$, their intensities decrease $60.3 \%, 26.3 \%$, and $25.9 \%$, respectively, with respect to ampicillin as measured in water. Presumably the milk solution results in much interference from other NSB molecules to hinder the absorption of ampicillin and leads to a decrease in the amount of target molecules upon SERS-active sites that may cause a reduction of Raman intensities. For the peaks at 1115 and $1447 \mathrm{~cm}^{-1}$, under a comparable condition, a similar trend with less sensitive changes can be found. It thus implies NSB molecules in milk solution are very influential to the peak of ampicillin at $1007 \mathrm{~cm}^{-1}$ (benzene ring vibration).
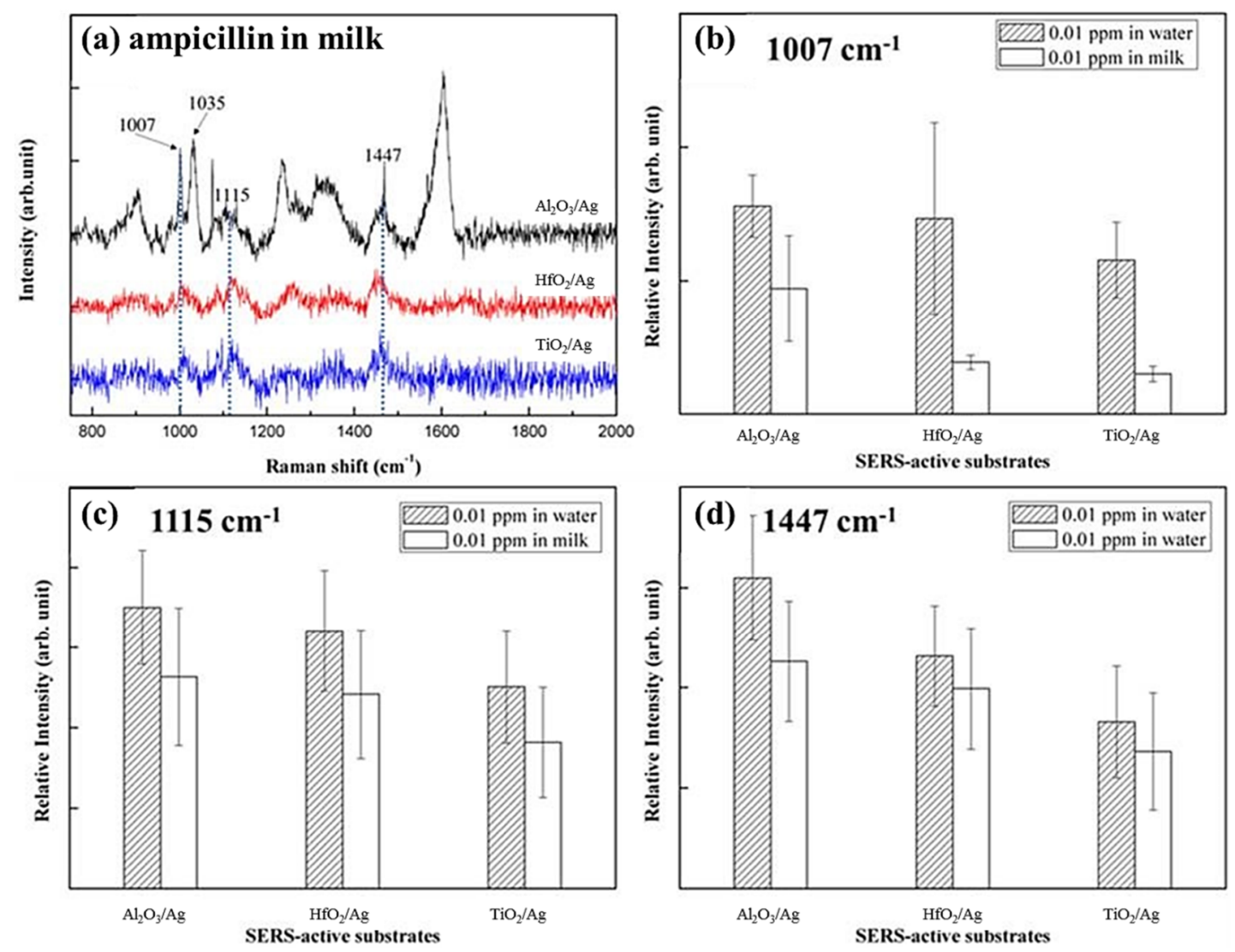

Figure 6. SERS spectra of ampicillin in milk with a concentration of $0.01 \mathrm{ppm}$ upon (a) $\mathrm{HfO}_{2} /, \mathrm{Al}_{2} \mathrm{O}_{3} /$, and $\mathrm{TiO}_{2} / \mathrm{Ag}$ HNS were shown. By taking different characteristic peaks (b) $1007 \mathrm{~cm}^{-1}$, (c) $1115 \mathrm{~cm}^{-1}$, and (d) $1447 \mathrm{~cm}^{-1}$ in water or in milk solution, their relative intensities were respectively compared. 


\subsection{Schematic Description of Ampicillin Detection in Water and in Milk Solution}

In Figure 7a,b, possible SERS mechanisms of Di NPs/Ag HNS are respectively illustrated for trace detections of residual ampicillin in water and in milk solution. In Figure 7a, the arrows represent the incident light rays. The direction of the light is scattered by HNSs that increases the probability of interactions with adsorbates. The main electromagnetic effect area is anticipated to happen: (i) in surface plasmon resonances of Ag HNS owing to the incident lights and electron transfers from the contact of Di NPs and Ag surface and (ii) upon Raman-active sites, which are distributed among Ag shells with cavities where "hot spots" are formed when target molecules are attached and a Raman laser with an appropriate wavelength induced. In addition, the light on NPs induces the conduction electrons to oscillate collectively with a resonant frequency that depends on the nanoparticles' size, shape, composition, inter-particle distance, and environment (e.g., dielectric properties such as the inclusion of the dielectric edges may create additional hotspots). In the particular case of Ag NPs, the LSPR yields exceptionally high absorption coefficients and scattering properties within the UV/visible wavelength range. The SPR of Ag NPs ( 420 nm, depending on their size) is obvious due to their spherical nature. The dielectric materials like $\mathrm{Al}_{2} \mathrm{O}_{3}, \mathrm{TiO}_{2}$, or $\mathrm{HfO}_{2}$ coating can shift the band to higher wavelengths.

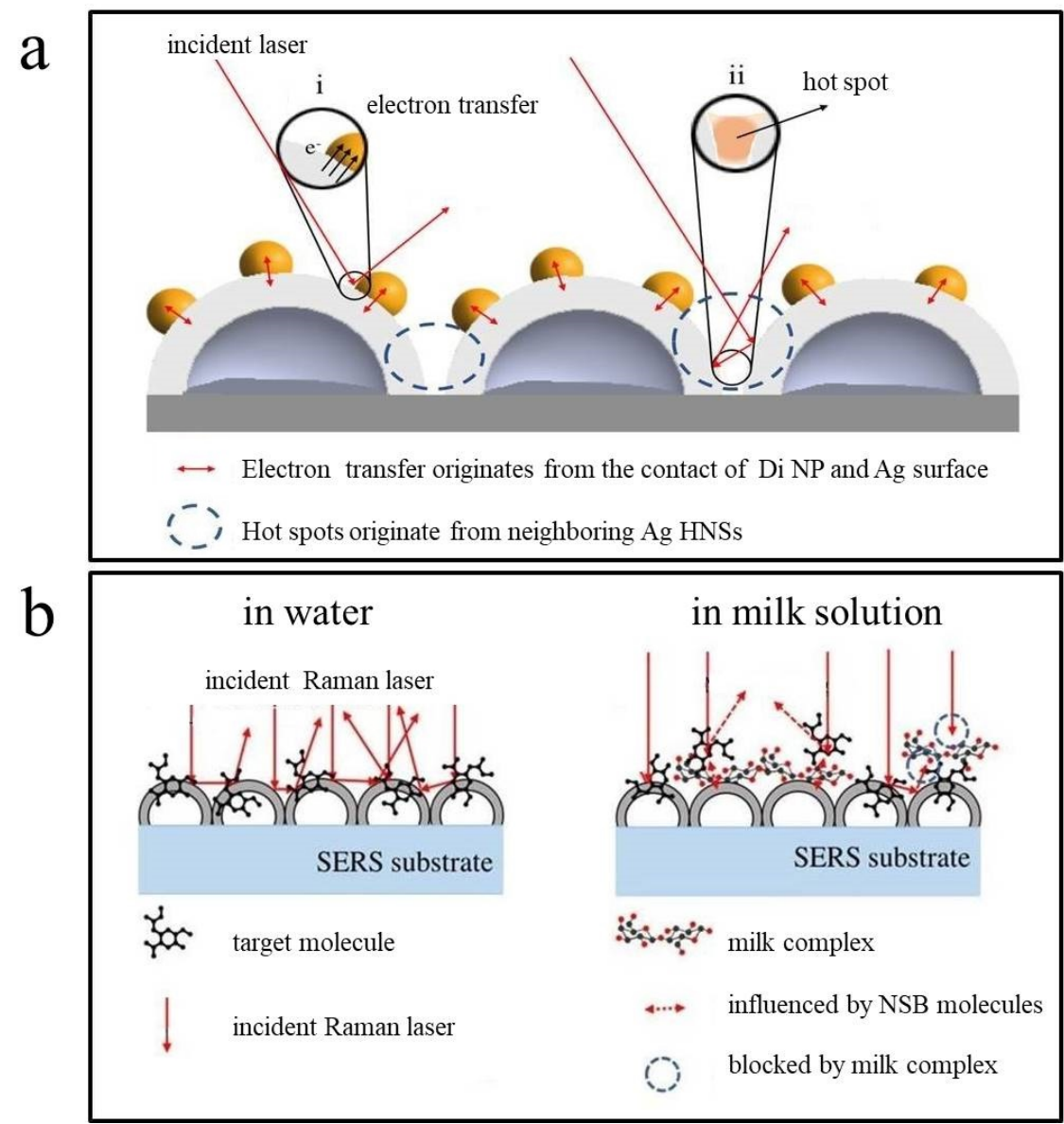

Figure 7. Schematic diagrams of (a) the main electromagnetic enhancement areas: when the incident lights are appropriately introduced, (i) electron transfers from the contacts at the interface between Di NPs and Ag surface occur, while (ii) upon Raman-active sites, neighboring Ag shells with cavities form "hot spots" and (b) SERS mechanism of Di NPs/Ag HNS with the inclusion of ampicillin in water and in milk solution. Ampicillin molecules in water attach upon Di NPs/Ag HNS, making its SERS-active signals enhanced. In milk solution, NSB molecules are also adsorbed upon Di NPs/Ag HNS, making only a part of Ampicillin molecules attach to the surfaces of Di NPs/Ag HNS. 
In the practical cases, a milk solution contains many NSB molecules that may hinder the absorption of ampicillin to be measured on SERS-active sites and therefore decrease Raman signals, in particular for the main peak at $1007 \mathrm{~cm}^{-1}$. In Figure $7 \mathrm{~b}$, the incident laser interacts with ampicillin on Di NPs/Ag HNS in water and milk solution is illustrated. Ampicillin is expected to attach upon Di NPs/Ag HNS in water, making its SERS-active signals enhanced. In milk solution, non-target or NSB molecules such as the residues of sugar and protein are also adsorbed upon Di NPs/Ag HNS, making a part of ampicillin molecules indirectly attached to the surfaces of Di NPs/Ag HNS. The presence of NSB molecules tends to lengthen the distance of ampicillin with SERS-active sites and thereafter relax the effect of SERS for its different characteristic peaks. It is likely that Di NPs may act as a dielectric spacer for Ag HNS that reduce the chemisorption of NSB molecules on Ag shell surface; further study on the influence of overall SERS property is required.

As described in Figure 7a,b, Raman fingerprints of ampicillin can be clearly defined using SERS-active substrates, $\mathrm{HfO}_{2} /, \mathrm{TiO}_{2} /$, and $\mathrm{Al}_{2} \mathrm{O}_{3} / \mathrm{Ag}$ HNS; their detection limit can be as low as $0.01 \mathrm{ppm}$. In the case of milk solution, the interference from NSB molecules in milk solution may occur that significantly reduces the measured intensity of ampicillin molecules on SERS-active surface. A physical method to shorten the distance of target molecules with hot-spot areas by e.g., activating the substrate for improving high coverage rate of target molecules or reducing the absorption of NSB molecules is therefore suggested.

\section{Conclusions}

In this study, the removal of PS_B is subsequently used as the template for forming HNS with a cavity in Ag HNS, followed by depositing Di NPs and constructed as Di NPs/Ag HNS. The as-formed Di NPs/Ag HNS obtains an integrated SERS property with the synergy from the characteristic of Ag as a SERS-active surface, an enhanced plasmonic effect inside Ag shell, and the contribution of dielectric property at Ag shell and Di NPs interface when a Raman laser with an appropriate wavelength is induced. The results demonstrate that a cavity with small diameter and Di NPs with low dielectric constant will result in a higher EF. In a practical application for trace detection of ampicillin in water, SERS intensities increase with the addition of ampicillin for all these three substrates, while $\mathrm{Al}_{2} \mathrm{O}_{3} / \mathrm{Ag}$ HNS exhibits sensitivity with the increased concentration of ampicillin, in consistence with its low dielectric constant. For the case of detecting ampicillin in milk solution, Di NPs/Ag HNS is competent to achieve trace detection of Ampicillin as low as $0.01 \mathrm{ppm}$. However, for detecting Ampicillin on the respective $\mathrm{Al}_{2} \mathrm{O}_{3} /, \mathrm{HfO}_{2} /$, and $\mathrm{TiO}_{2} / \mathrm{Ag}$ HNS in milk solution, SERS intensity at the main peak of $1007 \mathrm{~cm}^{-1}$ decrease up to $60.3 \%$ with respect to that measured in water. The presence of NSB molecules tends to lengthen the distance of Ampicillin with SERS-active sites and thereafter relax the effect of SERS for its different characteristic peaks. A possible SERS mechanism of Di NPs/Ag HNS for trace detection of Ampicillin in water and in milk solution is proposed: when a Raman laser with an appropriate wavelength is induced, the main electromagnetic effect is particularly resulted at the interface of Di NPs and Ag shells where electron transfers from the contacts of Di NPs and Ag surface occur and the distribution of "hot spots" arises along Ag shells with cavities. For trace detection of ampicillin in milk solution, as compared with that in water, additional NSB molecules, prior to the attachment of ampicillin upon Di NPs/Ag HNS, may significantly reduce the measured SERS intensity of ampicillin upon SERS-active sites. An effective method to shorten the distance between target molecules and hot-spot areas or to reduce the absorption of NSB molecules is therefore proposed.

\section{Highlights}

- Ag HNS is prepared by a template-assisted method, followed by e-beam evaporated Di NPs, and formed as Di NPs/Ag HNS.

- $\mathrm{Al}_{2} \mathrm{O}_{3} / \mathrm{Ag}$ HNS with low dielectric constant and smaller diameter of HNS obtains higher SERS enhancement factor. 
- The main electromagnetic effect of Di NPs/Ag HNS occurs at the interfaces of Di NPs, the surface of Ag shell, and the space of cavity.

- For all Di NPs/Ag HNS, trace detection of ampicillin in water is efficient, SERS intensities increase with the addition of ampicillin.

- Ampicillin in milk solution is influenced by non-specific binding molecules that lengthen the distance of ampicillin with SERS-active sites.

Author Contributions: Methodology, J.-W.Y. and K.S.; formal analysis, H.L. and J.S.; investigation, G.D.C.; data curation, W.-E.F. and B.H.L.; writing-original draft preparation, H.L.; writing-review and editing, J.S.; supervision, J.-D.L. All authors have read and agree to the published version of the manuscript.

Funding: This research received grant from the Headquarter of University Advancement at National Cheng Kung University (NCKU), sponsored by the Taiwan Ministry of Science and Technology under Grant Nos. 108-2218-E-006-054-MY3 and 108-2811-E-006-535.

Conflicts of Interest: The authors declare no conflict of interest.

\section{References}

1. Pu, H.; Xiao, W.; Sun, D. SERS-microfluidic systems: A potential platform for rapid analysis of food contaminants. Trends Food Sci. Technol. 2017, 70, 114-126. [CrossRef]

2. Dincer, C.; Bruch, R.; Costa-Rama, E.; Fernández-Abedul, M.T.; Merkoçi, A.; Manz, A.; Urban, G.A.; Güder, F. Disposable Sensors in Diagnostics, Food, and Environmental Monitoring. Adv. Mater. 2019, 31, 1806739. [CrossRef] [PubMed]

3. Levard, C.; Hotze, E.M.; Lowry, G.V.; Brown, G.E. Environmental transformations of silver nanoparticles: Impact on stability and toxicity. Environ. Sci. Technol. 2012, 46, 6900-6914. [CrossRef] [PubMed]

4. He, H.; Sun, D.W.; Pu, H.; Chen, L.; Lin, L. Applications of Raman spectroscopic techniques for quality and safety evaluation of milk: A review of recent developments. Crit. Rev. Food Sci. Nutr. 2019, 59, 770-793. [CrossRef] [PubMed]

5. Tian, Y.; Wang, Y.; Wu, S.; Sun, Z.; Gong, B. Preparation of ampicillin surface molecularly imprinted polymers for its selective recognition of ampicillin in eggs samples. Int. J. Anal. Chem. 2018, 2018, 5897381. [CrossRef] [PubMed]

6. Cordero, C.; Kiefl, J.; Reichenbach, S.E.; Bicchi, C. Characterization of odorant patterns by comprehensive two-dimensional gas chromatography: A challenge in omic studies. TrAC Trends Anal. Chem. 2019, 113, 364-378. [CrossRef]

7. Garza, B.; Echeverria, A.; Gonzalez, F.; Castillo, O.; Eubanks, T.; Bandyopadhyay, D. Phytochemical investigation of Magnolia grandiflora green seed cones: Analytical and phytoceutical studies. Food Sci. Nutr. 2019, 7, 1761-1767. [CrossRef]

8. Faraji, M. Determination of some red dyes in food samples using a hydrophobic deep eutectic solvent-based vortex assisted dispersive liquid-liquid microextraction coupled with high performance liquid chromatography. J. Chromatogr. A 2019, 1591, 15-23. [CrossRef]

9. Banholzer, M.J.; Millstone, J.E.; Qin, L.; Mirkin, C.A. Rationally designed nanostructures for surface-enhanced Raman spectroscopy. Chem. Soc. Rev. 2008, 37, 885-897. [CrossRef]

10. Chen, G.; Cao, P.; Liu, R. A multi-residue method for fast determination of pesticides in tea by ultra performance liquid chromatography-electrospray tandem mass spectrometry combined with modified QuEChERS sample preparation procedure. Food Chem. 2011, 125, 1406-1411. [CrossRef]

11. Tan, W.A.; Zhao, Y.; Sivashanmugan, K.; Alan, X. Quantitative TLC-SERS detection of histamine in seafood with support vector machine analysis. Food Control 2019, 103, 111-118. [CrossRef] [PubMed]

12. Yaseen, T.; Sun, D.W.; Cheng, J.H. Raman imaging for food quality and safety evaluation: Fundamentals and applications. Trends Food Sci. Technol. 2017, 62, 177-189. [CrossRef]

13. Hong, S.; Li, X. Optimal Size of Gold Nanoparticles for Surface-Enhanced Raman Spectroscopy under Different Conditions. J. Nanomater. 2013, 2013, 790323. [CrossRef]

14. Lee, H.; Liao, J.-D.; Sivashanmugan, K.; Liu, B.; Fu, W.; Chen, C.-C.; Chen, G.; Juang, Y.-D. Gold Nanoparticle-Coated ZrO2-Nanofiber Surface as a SERS-Active Substrate for Trace Detection of Pesticide Residue. Nanomaterials 2018, 8, 402. [CrossRef] 
15. Ding, S.Y.; Yi, J.; Li, J.F.; Ren, B.; Wu, D.Y.; Panneerselvam, R.; Tian, Z.Q. Nanostructure-based plasmon-enhanced Raman spectroscopy for surface analysis of materials. Nat. Rev. Mater. 2016, 1, 16021. [CrossRef]

16. Liu, B.; Han, G.; Zhang, Z.; Liu, R.; Jiang, C.; Wang, S.; Han, M.Y. Shell thickness-dependent Raman enhancement for rapid identification and detection of pesticide residues at fruit peels. Anal. Chem. 2012, 84, 255-261. [CrossRef] [PubMed]

17. Sivashanmugan, K.; Liao, J.; Der Liu, B.H.; Yao, C.K. Focused-ion-beam-fabricated Au nanorods coupled with Ag nanoparticles used as surface-enhanced Raman scattering-active substrate for analyzing trace melamine constituents in solution. Anal. Chim. Acta 2013, 800, 56-64. [CrossRef] [PubMed]

18. Guerrini, L.; Graham, D. Molecularly-mediated assemblies of plasmonic nanoparticles for Surface-Enhanced Raman Spectroscopy applications. Chem. Soc. Rev. 2012, 41, 7085-7107. [CrossRef]

19. Lee, A.; Andrade, G.F.S.; Ahmed, A.; Souza, M.L.; Coombs, N.; Tumarkin, E.; Liu, K.; Gordon, R.; Brolo, A.G.; Kumacheva, E. Probing dynamic generation of hot-spots in self-assembled chains of gold nanorods by surface-enhanced raman scattering. J. Am. Chem. Soc. 2011, 133, 7563-7570. [CrossRef]

20. Sivashanmugan, K.; Liao, J.; Der Liu, B.H.; Yao, C.K.; Luo, S.C. Ag nanoclusters on ZnO nanodome array as hybrid SERS-active substrate for trace detection of malachite green. Sens. Actuators B Chem. 2015, 207, 430-436. [CrossRef]

21. Dao, T.C.; Luong, T.Q.N.; Cao, T.A.; Kieu, N.M. High-sensitive SERS detection of thiram with silver nanodendrites substrate. Nat. Sci.-Nanosci. Nanotechnol. 2019, 10, 025012. [CrossRef]

22. Xie, H.N.; Larmour, I.A.; Smith, W.E.; Faulds, K.; Graham, D. Surface-enhanced Raman scattering investigation of hollow gold nanospheres. J. Phys. Chem. C 2012, 116, 8338-8342. [CrossRef]

23. Wang, X.; Wang, C.; Cheng, L.; Lee, S.T.; Liu, Z. Noble metal coated single-walled carbon nanotubes for applications in surface enhanced raman scattering imaging and photothermal therapy. J. Am. Chem. Soc. 2012, 134, 7414-7422. [CrossRef]

24. Wolosiuk, A.; Tognalli, N.G.; Martínez, E.D.; Granada, M.; Fuertes, M.C.; Troiani, H.; Bilmes, S.A.; Fainstein, A.; Soler-Illia, G.J.A.A. Silver nanoparticle-mesoporous oxide nanocomposite thin films: A platform for spatially homogeneous SERS-active substrates with enhanced stability. ACS Appl. Mater. Interfaces 2014, 6, 5263-5272. [CrossRef] [PubMed]

25. Wang, J.; Hassan, M.M.; Ahmad, W.; Jiao, T.; Xu, Y.; Li, H.; Ouyang, Q.; Guo, Z.; Chen, Q. A highly structured hollow ZnO@Ag nanosphere SERS substrate for sensing traces of nitrate and nitrite species in pickled food. Sens. Actuators B Chem. 2019, 285, 302-309. [CrossRef]

26. Wang, H.; Li, K.B.; Xu, C.; Xu, S.C.; Li, G.H. Large-scale solvothermal synthesis of Ag nanocubes with high SERS activity. J. Alloys Compd. 2019, 772, 150-156. [CrossRef]

27. Li, S.; Wang, Q.; Song, X.; Bu, Y. A green and general strategy for the synthesis of hollow $\mathrm{Ag} / \mathrm{CdS}$ nanocomposites for superior SERS performance. CrystEngComm 2019, 21, 3709-3720. [CrossRef]

28. Yin, J.; Zang, Y.; Yue, C.; Wu, Z.; Wu, S.; Li, J.; Wu, Z. Ag nanoparticle/ZnO hollow nanosphere arrays: Large scale synthesis and surface plasmon resonance effect induced Raman scattering enhancement. J. Mater. Chem. 2012, 22, 7902-7909. [CrossRef]

29. Wu, S.; Chen, Z.; Wang, T.; Ji, X. A facile approach for the fabrication of Au/ZnO-hollow-sphere-monolayer thin films and their photocatalytic properties. Appl. Surf. Sci. 2017, 412, 69-76. [CrossRef]

30. White, I.; Oveys, H.; Fan, X. Increasing the enhancement of SERS with dielectric microsphere resonators. Spectrosc. Springf. Eugene Duluth 2006, 21, 36-42.

31. Anandan, S.; Kumar, P.S.; Pugazhenthiran, N.; Madhavan, J.; Maruthamuthu, P. Effect of loaded silver nanoparticles on $\mathrm{TiO}_{2}$ for photocatalytic degradation of Acid Red 88. Sol. Energy Mater. Sol. Cells 2008, 92, 929-937. [CrossRef]

32. Ma, L.; Wang, J.; Huang, H.; Zhang, Z.; Li, X.; Fan, Y. Simultaneous Thermal Stability and Ultrahigh Sensitivity of Heterojunction SERS Substrates. Nanomaterials 2019, 9, 830. [CrossRef] [PubMed]

33. Kleinman, S.L.; Frontiera, R.R.; Henry, A.I.; Dieringer, J.A.; Van Duyne, R.P. Creating, characterizing, and controlling chemistry with SERS hot spots. Phys. Chem. Chem. Phys. 2013, 15, 21-36. [CrossRef] [PubMed]

34. Ma, L.; Wu, H.; Huang, Y.; Zou, S.; Li, J.; Zhang, Z. High-Performance Real-Time SERS Detection with Recyclable Ag Nanorods@HfO2 Substrates. ACS Appl. Mater. Interfaces 2016, 8, 27162-27168. [CrossRef] [PubMed] 
35. Hong, K.Y.; de Albuquerque, C.D.L.; Poppi, R.J.; Brolo, A.G. Determination of aqueous antibiotic solutions using SERS nanogratings. Anal. Chim. Acta 2017, 982, 148-155. [CrossRef]

36. Xu, Y.; Kutsanedzie, F.Y.H.; Hassan, M.M.; Li, H.; Chen, Q. Synthesized Au NPs@silica composite as surface-enhanced Raman spectroscopy (SERS) substrate for fast sensing trace contaminant in milk. Spectrochim. Acta A Mol. Biomol. Spectrosc. 2019, 206, 405-412. [CrossRef]

37. Im, S.H.; Lim, Y.T.; Suh, D.J.; Park, O.O. Three-Dimensional Self-Assembly of Colloids at a Water-Air Interface: A Novel Technique for the Fabrication of Photonic Bandgap Crystals. Adv. Mater. 2002, 14, 1367-1369. [CrossRef]

38. Craig, A.P.; Franca, A.S.; Irudayaraj, J. Surface-Enhanced Raman Spectroscopy Applied to Food Safety. Annu. Rev. Food Sci. Technol. 2013, 4, 369-380. [CrossRef]

39. Andreou, C.; Mirsafavi, R.; Moskovits, M.; Meinhart, C.D. Detection of low concentrations of ampicillin in milk. Analyst 2015, 140, 5003-5005. [CrossRef]

40. Kuznetsov, A.I.; Miroshnichenko, A.E.; Brongersma, M.L.; Kivshar, Y.S.; Luk'yanchuk, B. Optically resonant dielectric nanostructures. Science 2016, 354. [CrossRef]

41. Yesilkoy, F.; Arvelo, E.R.; Jahani, Y.; Liu, M.; Tittl, A.; Cevher, V.; Kivshar, Y.; Altug, H. Ultrasensitive hyperspectral imaging and biodetection enabled by dielectric metasurfaces. Nat. Photonics 2019, 13, 390-396. [CrossRef]

42. Wang, K.; Sun, D.W.; Pu, H.; Wei, Q. Shell thickness-dependent Au@Ag nanoparticles aggregates for high-performance SERS applications. Talanta 2019, 195, 506-515. [CrossRef] [PubMed]

43. Chang, J.; Zhang, A.; Huang, Z.; Chen, Y.; Zhang, Q.; Cui, D. Monodisperse Au@Ag core-shell nanoprobes with ultrasensitive SERS-activity for rapid identification and Raman imaging of living cancer cells. Talanta 2019, 198, 45-54. [CrossRef] [PubMed]

44. Sitjar, J.; Liao, J.-D.; Lee, H.; Liu, B.H.; Fu, W. SERS-Active Substrate with Collective Amplification Design for Trace Analysis of Pesticides. Nanomaterials 2019, 9, 664. [CrossRef] [PubMed]

45. Li, X.; Zhang, Y.; Shen, Z.X.; Fan, H.J. Highly ordered arrays of particle-in-bowl plasmonic nanostructures for surface-enhanced raman scattering. Small 2012, 8, 2548-2554. [CrossRef]

46. Pisarek, M.; Roguska, A.; Kudelski, A.; Andrzejczuk, M.; Janik-Czachor, M.; Kurzydłowski, K.J. The role of Ag particles deposited on $\mathrm{TiO}_{2}$ or $\mathrm{Al}_{2} \mathrm{O}_{3}$ self-organized nanoporous layers in their behavior as SERS-active and biomedical substrates. Mater. Chem. Phys. 2013, 139, 55-65. [CrossRef]

47. Bohr, M.T.; Chau, R.S.; Ghani, T.; Mistry, K. The high-k solution. IEEE Spectr. 2007, 44, 29-35. [CrossRef]

48. Le Ru, E.C.; Blackie, E.; Meyer, M.; Etchegoint, P.G. Surface enhanced raman scattering enhancement factors: A comprehensive study. J. Phys. Chem. C 2007, 111, 13794-13803. [CrossRef]

49. El-Zahry, M.R.; Refaat, I.H.; Mohamed, H.A.; Rosenberg, E.; Lendl, B. Utility of surface enhanced Raman spectroscopy (SERS) for elucidation and simultaneous determination of some penicillins and penicilloic acid using hydroxylamine silver nanoparticles. Talanta 2015, 144, 710-716. [CrossRef]

50. Sivashanmugan, K.; Lee, H.; Syu, C.; Liu, B.H.; Liao, J. Nanoplasmonic Au/Ag/Au nanorod arrays as SERS-active substrate for the detection of pesticides residue. J. Taiwan Inst. Chem. Eng. 2017, 75, 287-291. [CrossRef]

51. Feng, S.; Lock, A.L.; Garnsworthy, P.C. Technical Note: A Rapid Lipid Separation Method for Determining Fatty Acid Composition of Milk. J. Dairy Sci. 2004, 87, 3785-3788. [CrossRef]

52. Khan, A.; Xhibo, F.; Yücel, N.; Turan, S. Synthesis and Characterization of Novel Nanomaterials for SERS Biomedical/Environmental Application Project Supervisors. Available online: https: //www.researchgate.net/publication/336498006_Synthesis_and_Characterization_of_Novel_Nanomaterials_ for_SERS_BiomedicalEnvironmental_Application_Project_Supervisors (accessed on 15 April 2020).

53. Aguilar-Hernández, I.; Afseth, N.K.; López-Luke, T.; Contreras-Torres, F.F.; Wold, J.P.; Ornelas-Soto, N. Surface enhanced Raman spectroscopy of phenolic antioxidants: A systematic evaluation of ferulic acid, p-coumaric acid, caffeic acid and sinapic acid. Vib. Spectrosc. 2017, 89, 113-122. [CrossRef]

(C) 2020 by the authors. Licensee MDPI, Basel, Switzerland. This article is an open access article distributed under the terms and conditions of the Creative Commons Attribution (CC BY) license (http://creativecommons.org/licenses/by/4.0/). 